\title{
Spinal Nerve Tumors \\ - Clinical and Operative Experiences of 53 Cases -
}

\author{
Tomokatsu Hori, Kintomo Takakura, Keiji Sano*
}

\author{
Department of Neurosurgery, Tokyo Women's Medical College \\ Department of Neurosurgery, Tokyo University School of Medicine* \\ Tokyo, Japan
}

\begin{abstract}
Fifty-three patients with spinal nerve tumors, including 9 neurofibromas and 44 schwannomas were operated on in our clinics between 1962 and 1997.

Frequent initial symptoms were neuralgic pain in 26 cases, weakness of the region of the involved nerve(s) in 12, and the dysesthesia or numbness in 8. Patients showing only neuralgic pain or weakness of the involved nerve(s) or asymptomatic were classified as Stage I (5 patients); those presenting neurological dysfunction but were able to walk by themselves were classified as Stage II (21 patients); those presenting paraplegia and consequently were unable to walk were classified as Stage III (23 patients); and those presenting tetraplegia and were unable to sit were classified as Stage IV (4 patients). All patients in Stage IV had cervical tumors and 2 of them were neurofibromas. The presence of vesico-urinary disturbance was closely correlated with the exacerbation of neurological dysfunction: In Stage I, there was no vesico-urinary dysfunction, in Stage II 9.5\%, in Stage III 78.3\%, and in Stage IV 100\%. Location of the tumors in relation to the dura mater revealed 36 tumors were intradural, 7 were purely extradural, and 10 were dumbbell type. The follow-up review of these 53 cases showed good functional recovery except for 1 case of neurofibroma in Stage IV who is now bedridden. Postoperative neurological recovery is satisfactory in all cases, and even if the tumor originated from anterior roots of C5 and/or C6, risks of neurological deficit after resection of the involved nerves were negligible.
\end{abstract}

Key word: schwannoma, spinal nerve tumor, neurofibroma, dumbbell, von Recklinghausen's disease

Spinal Surgery $12(3): 263 \sim 272,1998$

\section{INTRODUCTION}

Spinal nerve tumors are common space occupying lesions in the spinal canal in Japan [9] and the Republic of China [3], and many reports have been published concerning their clinical characteristics, diagnosis, treatment, and operative results $[2,5,6,7$, $8,11,12,14]$.

The early signs and symptoms of this benign lesion are said to be relatively unremarkable and can remain

(Received : January 12, 1998, Accepted : September 4, 1998)

東京女子医科大学 脳神経外科, 東京大学医学部 脳神経外科*（連絡先：堀 智勝 ү162-0054 東京都新宿区河田町8-1 東京女子医科 大学 脳神経外科) Address reprint request to: Tomokatsu Hori, M.D. Department of Neurosurgery, Tokyo Women's Medical College, 8-1, Kawada-cho, Shinjuku-ku, Tokyo, 162-0054, Japan 


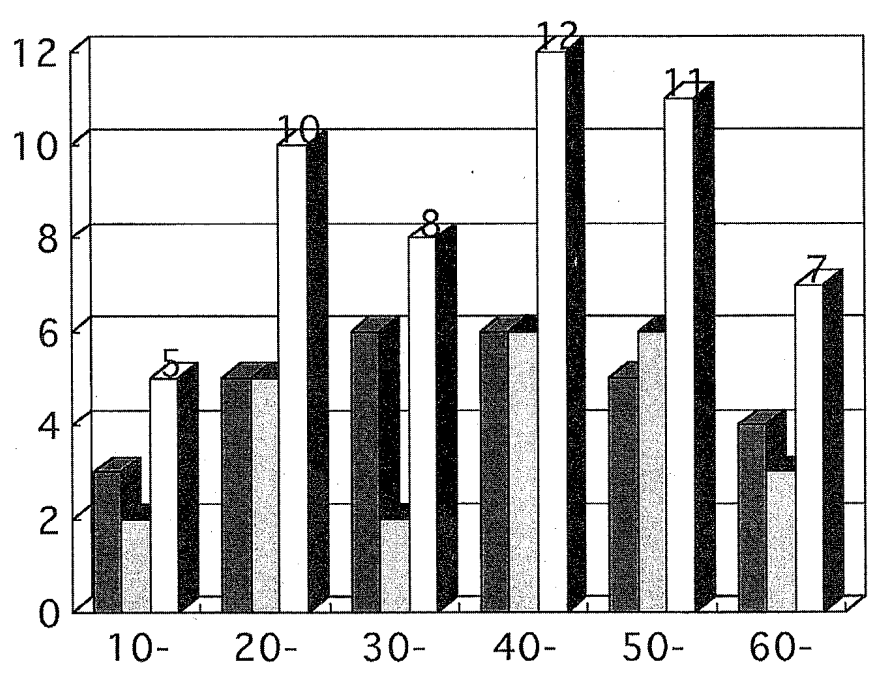

Familial Spinal Cord Tumor

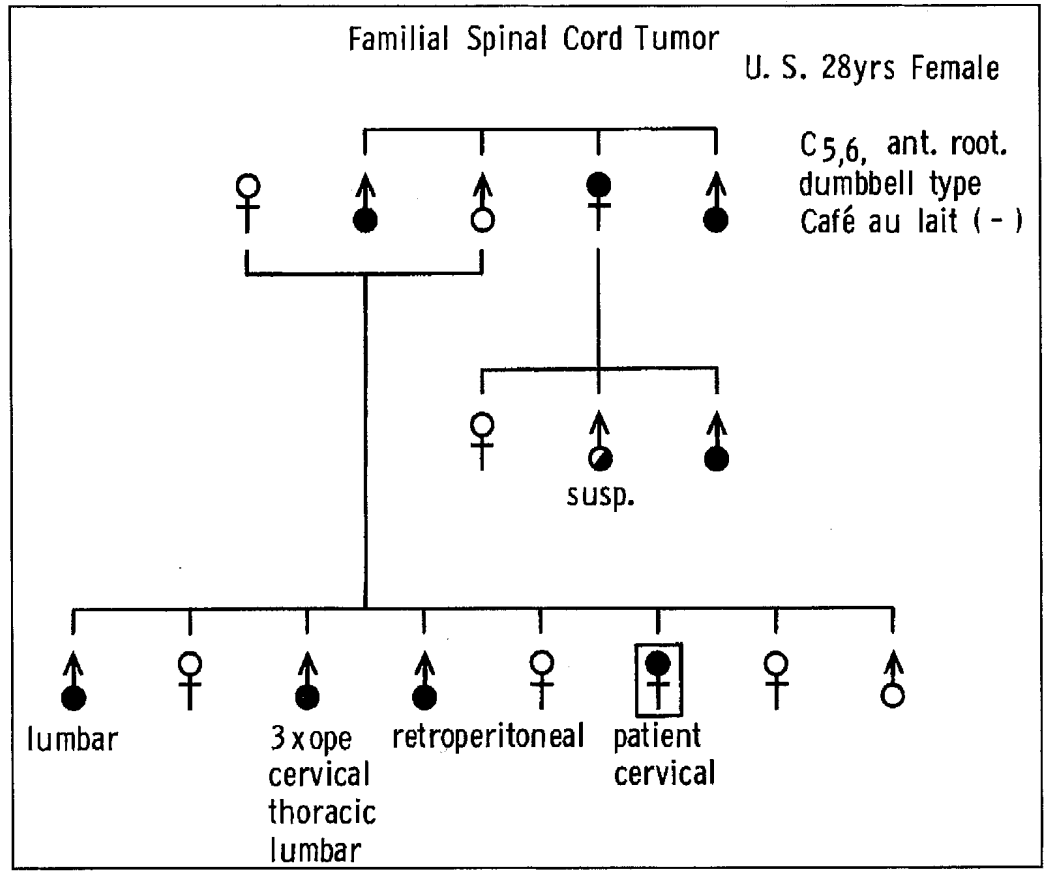

Fig 1: Age and sex distribution of 53 cases of spinal nerve tumors at operation.

The patients included in this study were 24 women and 29 men. Of these 53 tumors, the age of the patients at operation ranged from 10 to 69 years with the average of 41.2 years.

Fig 2: Case 43 is a 28-year-old woman who had a schwannoma at C5 and C6 anterior roots and a member of familial spinal cord tumors. Four out of her 8 siblings had spinal tumors and 4 other members of her relatives were also afflicted with spinal tumors. unrecognized until serious and often tragic neurological sequelae occur. This report includes a detailed analysis of clinical findings and operative results in 53 cases of nerve tumors of the spinal cord including 44 schwannomas and 9 neurofibromas. A significant number of these patients were at the terminal stage of this disease; that is, over half of these patients were paraplegic or tetraplegic at the time of operation.

Although early diagnosis and treatment of this disease entity are essential, long-term operative results indicate that the spinal cord has a considerable ability to recover its function $[10,13,15]$.

\section{SUMMARY OF CASES}

\section{< I. CLINICAL MATERIAL >}

From 1962 to 1982, 41 surgical cases of spinal nerve tumors were seen at the Department of Neurosurgery, University of Tokyo. A total of 2,189 brain tumors, and 104 spinal cord tumors were seen during that period. The 104 spinal cord tumors consisted of 41 
schwannomas or neurofibromas, 18 metastatic tumors, 12 meningiomas, and 33 other tumors. The ratio of nerve tumors to meningiomas was 3.4 to 1 . This study analyzed these 41 cases and 12 additional cases of spinal nerve tumors operated on by one of the authors (T.H.).

The patients included in this study were 24 women and 29 men (Fig 1). Of these 53 tumors, 38 involved the cervical segment of the spinal cord, 11 thoracic, 2 the lumbar, 1 cauda equina, and 1 sacral (Table 1). Thirty-eight tumors originated from posterior roots, 9 were from anterior roots, and 6 were derived from either anterior or posterior roots, namely, indefinite from the operative findings.

Thirty-six tumors were intradural, 10 were dumbbell type, and 7 were purely extradural. Five of the 10 dumbbell-type tumors were neurofibromas associated with von Recklinghausen's disease. The age of the patients at operation ranged from 10 to 69 years with the average of 41.2 years. The median length of the history for cervical neurinomas was 3.4 years, thoracic 3.2 years, lumbar 3.0 years, and cauda equina 14.0 years and indefinite for a sacral tumor.

Among the 53 cases, 9 were neurofibromas associated with von Recklinghausen's disease. Case 23 had double tumors at C6 and Th 10, but the thoracic tumor remained asymptomatic until the time of operation. Case 41 had bilateral C1-2 posterior roots tumors. Case 49 had also double tumors at C34 and Th 6. Case 43 was a 28 -year-old woman who had a schwannoma at C5-6 anterior roots and was a member of familial spinal cord tumors (Fig 2). As shown in Fig 2, 4 out of 8 her siblings had spinal tumors and 4 other members of her relatives were also afflicted with spinal tumors. Of the 53 cases, 5 were under 20 years of age, and 2 of them had von Recklinghausen's disease.

\section{< II. PRESENTING SYMPTOMS >}

Following neurological evaluation, all 53 cases underwent surgical removal of the tumors. Total removal of the tumors was accomplished in all but 10 cases. The localization and origin of the tumors were ascertained at operation, and histological examinations were performed on the operative specimens. Postoperatively, these patients were examined neurologically and were followed up.

\section{$<$ III. INITIAL SYMPTOMS >}

The most frequent initial symptoms were neuralgic pain in 23 cases $(43.4 \%)$, weakness of the region of the involved nerve(s) in $18(34.0 \%)$, and dysesthesia (numbness) in $8(15 \%$, Table 2$)$. In the early stages, these symptoms were often overlooked or misinterpreted as representing other diseases such as cervical spondylosis, multiple sclerosis, or syringomyelia. Other initial symptoms were stiffness, dullness, hot or cold dysesthesia, finger flexion, and bladder dysfunction (Table 2). Twenty-five tumors were situated on the right side of the cord, 27 were on the left, and only 1 was bilateral. The side of the initial symptom corresponded with that of the lesion in 43 cases $(81.1 \%)$, was contralateral in 3 cases, indefinite in 3 , and bilateral in 4 .

Nine patients had von Recklinghausen's disease. Although 6 out of 9 patients had other tumors in the neuraxis, 7 of them had only 1 spinal tumor, 1 had 2 neurofibromas in the same region, and the other had 2 neurofibromas, 1 of which remained asymptomatic until operation.

\section{< IV. NEUROLOGICAL FINDINGS > (Table 3)}

Radicular pain was the most common symptom, occurring in 39 cases $(73.6 \%)$. Myalgia of the calf muscles after prolonged gait was observed in 1 case. Dysesthesia, which was expressed by the patients as numbness was observed in 32 cases $(60.4 \%)$, tingling sensation, or either cold or hot dysesthesia [1], was observed in the hands in 10 cases, in the arms in 4, in the lower extremities in 15 , in the lower half of the body in 1 , and in one side of the body except for face in 1. A strangled sensation of the chest was observed in 3 cases. Edematous swelling of the extremities was seen in 6 cases. There was stereoanesthesia in 1 case, involuntary finger flexion in 2 , convulsion of the left half of the body in 1, and fasciculation of the 
Table 1: Patient distribution in function of neurological stages and locations

\begin{tabular}{lcccc}
\multicolumn{1}{c}{ Stage } & I & II & III & IV \\
Location & & & & \\
\hline Cervical & 2 & 17 & 15 & 4 \\
Thoracic & 1 & 4 & 6 & 0 \\
Lumbar & 0 & 0 & 2 & 0 \\
Cauda Equina & 1 & 0 & 0 & 0 \\
Sacral & 1 & 0 & 0 & 0
\end{tabular}

\footnotetext{
All Stage IV patients having the tumors at cervical region.

Stage I: Patients showing only neuralgic pain or weakness of the involved nerve(s) or no motor and sensory impairment with constipation only,

Stage II: Patients presenting motor and sensory disturbance, but able to walk by themselves, Stage III: Patients presenting paraplegia and consequently unable to walk,

Stage IV: Patients presenting tetraplegia and consequently unable to sit,
}

extremities in 1 case, anisocoria in 2 , dyspnea in 1 , and apnea under the control of an respirator was found in 1 .

\section{< V. WEAKNESS OF THE EXTREMITIES >}

Only 2 patients had no motor deficit preoperatively. Four patients had complete tetraplegia, 15 had minimal-to-severe weakness in all 4 extremities, and 4 had hemiparesis or hemiplegia. Two patients had paraparesis of the upper extremities, whereas 22 patients had paraparesis or paraplegia of the lower extremities. Two patients had monoparesis of an upper extremity and of a lower extremity. Two patients showed alternating monoparesis, that is, monoparesis in an upper extremity on one side and in the lower extremity on the other side. Among these 53 cases, 38 cervical tumors showed different modes of progression of motor paresis. There seemed to be a tendency for initial motor weakness to develop to the contralateral side (parallel type) in lower cervical tumors (C6-8).

\section{< VI. PREOPERATIVE GRADING OF NEUROLOGICAL DEFICITS >}

All 53 patients were symptomatic at preoperative evaluation and graded according to neurological dysfunction. Four patients showing only neuralgic pain or weakness of the involved nerve(s) and 1 patient (sacral schwannoma) with constipation only were classified as Stage I (9.4\%); 21 presenting motor and sensory disturbance but able to walk by themselves were classified as Stage II (39.6\%) ; 23 presenting paraplegia and consequently unable to walk were classified as Stage III (43.4\%) ; and 4 presenting tetraplegia and unable to sit were classified as Stage IV (7.5\%). They were further grouped according to the level of the tumors respectively as shown in Table 1.

\section{< VII. TYPES OF SENSORY DISTURBANCE >}

Sensory disturbances were also divided into 4 groups. Simple neuralgia or hypesthesia of the involved nerve(s) was observed in 18 cases and classified as Type I. The glove-and-stocking type of symmetrical sensory loss was observed in 2 cases and classified as Type II. The Brown-Sequard type of sensory disturbance was observed in 9 cases and classified as Type III. Incomplete or complete transection type of sensory disturbance was observed in 23 cases and classified as Type IV. 


\section{Table 2: Initial symptoms of 53 patients with spinal nerve tumors}

$\begin{array}{lc}\text { * Neuralgic pain } & 23 \\ \text { * Weakness } & 18 \\ \text { * Numbness(Shibire) } & 8 \\ \text { * Stiffness } & 2 \\ \text { * Dullness } & 1 \\ \text { * Cold sensation } & 1 \\ \text { * Hot sensation } & 1 \\ \text { * Finger flexion } & 1 \\ \text { * Baldder dysfunction } & 1 \\ \text { * Constipation } & 1\end{array}$

The most frequent initial symptoms were neuralgic pain in 23 cases (43.4\%). Weakness of the region of the involved nerve(s) was observed in 18 cases (34.0\%), and dysesthesia or numbness were observed in 8 cases $(15 \%)$.

Table 3: Frequency of various symptoms before surgery of spinal nerve tumors in 53 patients

\begin{tabular}{|c|c|c|c|}
\hline * Radicular pain & 39 & *Stereoanesthesia & 1 \\
\hline * Dysesthesia & & *Anisocoria & 2 \\
\hline Upper extremity & 14 & $*$ Hoarseness & 1 \\
\hline Arm & 4 & *Dyspnea/Apnea & 2 \\
\hline Hand & 10 & \multicolumn{2}{|c|}{ *Strangled sensation of chest } \\
\hline Lower extremity & 15 & & 3 \\
\hline \multirow[t]{2}{*}{ One side of the body } & 1 & \multicolumn{2}{|c|}{ * Strangled sensation of abdomen } \\
\hline & & & 3 \\
\hline Lower half of the body & 1 & *Stiffness & 6 \\
\hline Chest, abdomen & 1 & *Dullness & 2 \\
\hline * Vesico-urinary disturbance & 24 & \multicolumn{2}{|c|}{ *Edematous swelling of extremities } \\
\hline$*$ Involuntary finger flexion & 2 & & 6 \\
\hline * Hemiconvulsion & 1 & \multicolumn{2}{|c|}{ *Myalgia after prolonged gait } \\
\hline * Fasciculation & 1 & & 1 \\
\hline
\end{tabular}

In all cases, except for a sacral schwannoma, minimal to severe sensory disturbance was observed. Among the group of simple neuralgia or hypesthesia, even though their sensory disturbances were classified as Type I, 5 cases showed neurological disturbances classified as Stage III (unable to walk).

\section{< VIII. VESICO-URINARY DISTURBANCE >}

In 24 cases $(45.3 \%)$, vesico-urinary disturbances were observed. The presence of these disturbances was closely correlated with the advancement of neurological grading system. In Stage I, no patient showed vesico-urinary disturbance except for a slight constipation tendency of a patient of sacral 
schwannoma. In Stage II, two cases showed vesicourinary disturbance $(9.5 \%)$. In Stage III, 18 cases out of $23(78.3 \%)$ showed the disturbance. In Stage IV, all patients showed severe vesico-urinary disturbance necessitating catheterization.

\section{$<$ IX. OPERATION >}

All tumors were removed through the posterior route except for a case of sacral schwannoma. This 24year-old female had a huge right S3 schwannoma which had occupied the entire lower half of the retroperitoneal space as shown in Fig 3. This tumor was subtotally removed by anterior approach with collaboration of abdominal surgeons and urologists. Concerning 10 cases of dumbbell-type tumors, in 6 cases, the extradural tumor was completely removed electively by the anterior route at the second operation, and in the other 4 cases, the extradural tumors were removed as much as possible subcapsularly by posterior route. As postoperative recovery was remarkable in these 4 cases, further operation by the anterior approach was either refused by the patient or judged to be unnecessary by the physician. Follow-up results ranging from 4 months to 28 years have shown no reappearance of neurological deterioration in these 4 cases. In 2 cases of neurofibroma associated with von Recklinghausen's disease, the tumor was only partially removed. In a case of C2 schwannoma of the left posterior root, the patient developed sudden respiratory arrest and become tetraplegic 10 hours after the first operation. Emergency operation revealed a subpial hematoma which was successfully removed, and 33 years later the patient continues to lead a useful social life without undue neurological sequelae except for dysesthesia of the left half of the body.

For other cases, postoperative neurological recovery was remarkable. In a case of intradural extramedullary schwannoma of right C5-6 anterior roots, perioperative sequential changes of pain sensation (pin prick) are demonstrated in Fig 4. One month after surgery, pain sensation recovered sufficiently except for left lower half of the body. At follow-up questionnaire the patient reported disappearance of this deficit 6 months after the operation.

Concerning postoperative motor deficits, especially C5 and C6, no postoperative exacerbation of the weakness had been encountered in 4 cases of $\mathrm{C} 5$ and/or C6 anterior root tumors.

\section{< X. FOLLOW-UP RESULTS >}

All 5 of the Stage I patients (100\%) are leading useful, normal lives. Eighteen of the 21 Stage II patients $(85.7 \%)$ are also leading useful lives without signs of morbidity, but 3 others complain of pain or dysesthesia in various parts of the body. Eighteen of the 23 Stage III patient (78.3\%) lead useful lives, but the remaining 5 complain of various symptoms including dysesthesia (2), pain (2), stiffness (1), and dysuria (1). One of the 4 Stage IV patients is leading a completely normal life, but 2 other patients associated with von Recklinghausen's disease are troubled by morbidity. One patient can walk alone with cane but with some sensory disturbance. In his preoperative state, he had shown apnea and had been unconscious under respirator control. Subsequently he was again operated on to his thoracic neurofibroma. The other patient with a neurofibroma who also had bilateral acoustic tumors, has been bedridden since the last operation, which achieved only subtotal removal. The last patient of the right C5 anterior root schwannoma had suddenly deteriorated with intratumoral hemorrhage just one day before elective surgery, and after emergency operation the patient showed remarkable functional recovery except for a persistent dysesthesia of the right hand.

\section{DISCUSSION}

Tumors of the spinal cord and its coverings are relatively uncommon. In Nittner's review of 4,885 spinal cord tumors collected from the literature in 1976, there were 1,129 neurilemmomas $(23.1 \%)$ and 1,088 meningiomas [11]. The ratio of 

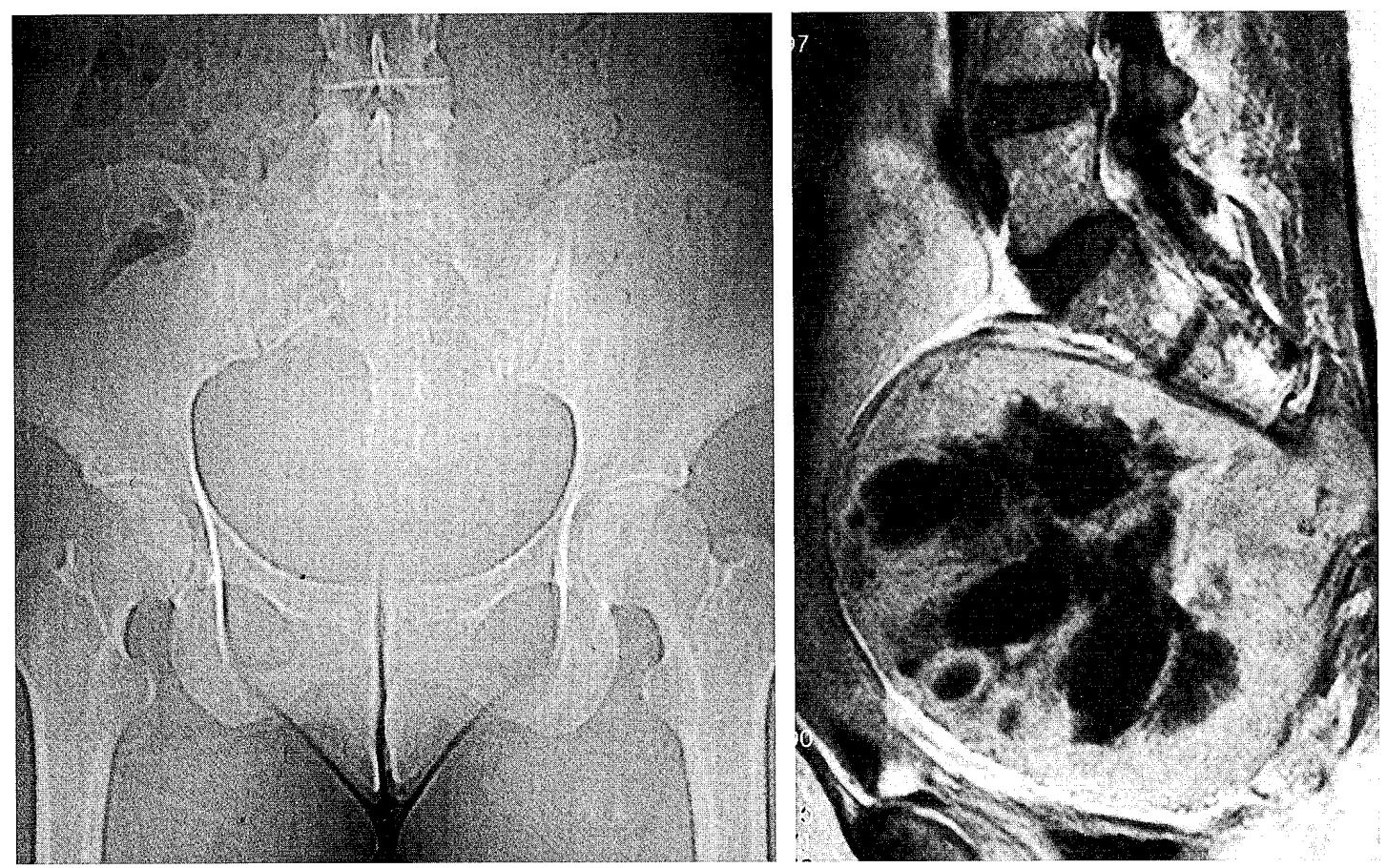

Fig 3: This 24-year-old woman had a huge right S3 schwannoma which had occupied the retroperitoneal space. The tumor was removed subtotally by anterior approach with collaboration of abdominal surgeons and urologists. Postoperative neurological impairment was nil.

Left: Plain X-ray film showing the dilatation of the right intervertebral foramen between S3 and S4. Right: Gadolinium enhanced sagittal MRI showing the extent of the tumor with central necrosis.

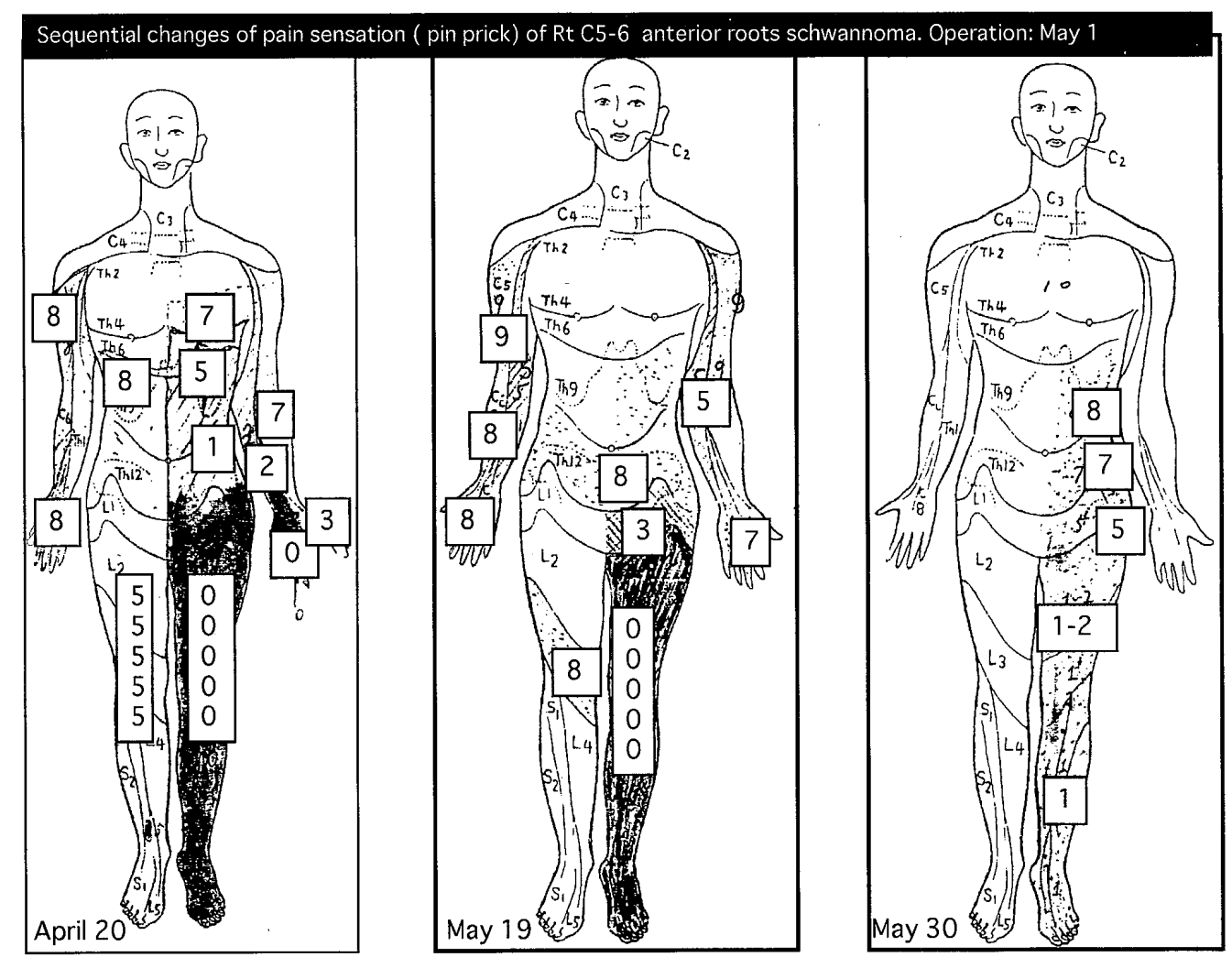

Fig 4: Perioperative sequential changes of pain sensation (pin prick) of a case of right C5 and C6 anterior roots schwannoma. Operation was performed on May 1, 1962. On May 30, just 1 month after the operation, remarkable recovery of pain sensation was observed which resolved completely 6 months after the operation. 
neurilemmomas to meningiomas in this series was 1.03 to 1 . In the present report, 41 spinal nerve tumors $(39.4 \%)$ were collected from 104 spinal tumors, whereas only 12 cases of meningiomas were found during that period. The ratio of spinal nerve tumors to meningiomas was 3.4 to 1 . This was clearly different not only from Nittner's series but also from other Western series [5, 6, 8, 14]. Other Japanese series also showed a higher incidence of schwannomas than meningiomas [9].

In this study, the tumors occurred most frequently in the cervical region $(38 / 53,71.7 \%)$, whereas in Western reports the tumors were reported to occur most frequently in the middle and lower thoracic regions $[2,4,8,11,12]$. In the large Japanese series of 223 neurinomas, 54 cases were in the cervical region $(24.2 \%)$, whereas 141 tumors were found in the thoracic region (63.2\%) [9]. From these results, the increased incidence of cervical spinal nerve tumors in our series seemed to be specific to our clinics [7]. The report of Umbach showed another higher incidencce of cervical than thoracic tumors in the literature [14].

Other features of our series included a male predominance (29/53 cases) and the existence of 5 cases under 20 years of age. Nine cases of neurofibroma were associated with von Recklinghausen's disease. Nine tumors were derived from anterior root(s) (17.0\%) and 38 from posterior $\operatorname{root}(\mathrm{s})(71.7 \%)$. No other reports have specified tumor origin. The initial symptom has been reported to be neuralgic pain in $72.3 \%$ of the cases [12]. In our series, neuralgic pain as the initial symptom occurred in $43.4 \%$, whereas weakness occurred in $34.0 \%$, and numbness in $15.1 \%$.

The side of the lesion correlated well with that of the initial symptoms. In 43 of 53 cases $(81.1 \%)$ the side of the lesion corresponded with the side of the initial symptoms of the disease.

All 53 cases were neurologically evaluated before surgery. Sensory disturbance was observed in all except for a sacral schwannoma, and motor weakness was observed in all but 2 (cauda equina tumor and sacral tumor). Other neurological findings included radicular pain $(73.6 \%)$, dysesthesia or numbness $(60.4 \%)$, and vesico-urinary disturbance $(45.3 \%)$.

Modes of progression of weakness were divided into initial ascending, descending, and parallel types. In lower cervical lesions (C6-C8), motor weakness were tended to develop to the contralateral side (parallel type).

Sensory disturbances were also classified into a neuralgia or hypesthesia group $(18 / 53,34.0 \%)$, glovestocking type (2 cases), Brown-Sequard type (9/53, $17.0 \%$ ), and incomplete or complete spinal cord transsection type $(23 / 53,43.4 \%)$. There was a complete or incomplete transsection of the spinal cord in over $40 \%$ of the cases, but in about $60 \%$, confusing clinical pictures resulted in delayed diagnosis and treatment.

Concerning vesico-urinary disturbance, it was not found in Stage I, in Stage II it was found in $9.5 \%$ of cases, in Stage III in 78.3\%, and in Stage IV in 100\%. Thus, progression of neurological symptoms correlated well with the incidence of associated vesico-urinary disturbance. After operation, vesicourinary disturbances ameliorated promptly, remaining in only 1 case each of Stage III and Stage IV.

Although spinal computerized tomography and magnetic resonance images are now available in neruosurgical practice, these careful and precise analyses of neurological symptoms associated with operative results are mandatory for the preoperative discussion with the patient and family about the final prognosis of this disease entity.

The follow-up period ranged from 3 months to 33 years. Three of 4 Stage IV patients became able to walk without assistance. These results showed that, although early diagnosis and treatment are essential in the treatment of spinal schwannomas or neurofibromas, surprisingly good functional recovery can be obtained, even in the terminal stage of tertraplegia with vesico-urinary disturbance caused by high cervical neurofibroma.

Kim et al. [10] reported that the spinal roots giving origin to schwannoma are frequently nonfunctional at 
the time of surgery, and risks of causing disabling neurological deficits after sacrificing these roots are small. Schultheiss and Gullotta [13] also reported that resection of relevant nerve roots in surgery of spinal neurinomas was possible without persisting neurological deficits. In our 4 cases, in whom the tumors originated from the $\mathrm{C} 5$ and/or C6 anterior $\operatorname{root}(\mathrm{s})$, no persistent motor deficits had been observed. In other tumors originating from $\mathrm{C} 7,8$ or L3 to S1, no persistent neurological motor deficits had been encountered so far. Probably normal preoperative EMG findings of affected region will assure the optimum functional results before surgery as reported by Kim et al. [10].

A case of huge neurofibroma with a diameter of over $5 \mathrm{~cm}$ from $\mathrm{C} 2-6$ who showed respiratory arrest and loss of consciousness and was under control of a respirator before surgery showed remarkable functional recovery 6 months after the operation, with complete removal of the intradural neurofibroma and subcapsular removal of the extradural tumor, the patient can walk by himself and leads a useful life.

In conclusion, this report presents the complexity of the neurological symptoms associated with spinal nerve tumors, and indicates that remarkable functional recovery or compensation is possible even for the severely disabling cases of spinal neurofibroma associated with von Recklinghausen's disease, when proper treatment is provided.

\section{REFEREENCES}

1. Beaty RA: Cold dysesthesia: A symptom of extramedullary tumors of the spinal cord. J Neurosurg 33: 75-78, 1970.

2. Broager G: Spinal neurinoma. A clinical study comprising 44 cases with a discussion of histological origin and with special reference to differential diagnosis against glioma and meningioma. Acta Psychiat Scand (Suppl) 85: 1241, 1953.

3. Cheng MK: Spinal cord tumors in the People's Republic of China: A statistical review.
Neurosurgery 10: 22-24, 1982.

4. Dinakar I, Balaparameswararao S: Myelographic features of spinal neurinomas. Int Surg 57: 730734, 1972.

5. Fields WS, Zulch KJ, Maslenikov V: High cervical neurinoma. Special neurologic and radiologic features. Zbl Neurochir 33: 89-102, 1972.

6. Fortuna A, Nolletti A, Nardi P, Caruso R: Spinal neurinomas and meningiomas in children. Acta Neurochir (Wien) 5: 329-341, 1981.

7. Hori T, Takakura K, Sano K: Spinal neurinomas Clinical analysis of 45 surgical cases. Neurol Med Chir (Tokyo) 24: 471-477, 1984.

8. Iraci G, Peserico L, Salar G: Intraspinal neurinomas and meningiomas. A clinical survey of 172 cases. Int Surg 56: 289-303, 1971.

9. Izumida S, Ikeda A: Summary of spinal tumors. Geka 29: 412-418, 1967 (in Japanese).

10. Kim P, Ebersold MJ, Onofrio BM, Quast LM: Surgery of spinal nerve schwannoma. Risk of neurological deficit after resection of involved root. J Neurosurg 71: 810-814, 1989.

11. Nittner K: Spinal meningiomas, neurinomas and neurofibromas and hourglass tumors, in Vinken PJ, Bruyn GW (eds): Handbook of Clinical Neurology, Vol 20, Amsterdam, North-Holand, 1976, pp177 - 322.

12. Salah S, Horcajada J, Perneczky A: Spinal neurinomas - A comprehensive clinical and statistical study on 47 cases. Neurochirurgia (Stuttg) 18: 77-84, 1975.

13. Schultheiss R, Gullotta G: Resection of relevant nerve roots in surgery of spinal neurinomas without persisting neurological deficit. Acta Neurochir 122: 91-96, 1993.

14. Umbach W: Klinik und Verlauf bei 192 spinalen prozessen mit besonderer berucksichtigung der gefabtumoren. Acta Neurochir 10: 167-193, 1962.

15. Yasuoka S, Okazaki H, Daube JR, MacCarty CS: Foramen magnum tumors. Analysis of 57 cases of benign extramedullary tumors. J Neurosurg 49: 828-838, 1978. 


\section{Co-Editor's comment : \\ Hiroshi Nakagawa \\ Aichi Medical University \\ Aichi, Japan}

I am greatly impressed by author's continuous and highly diligent work on neurological evaluation and clinical analysis of spinal nerve tumors over 35 years. Maticulous analysis of neurological symptoms and signs of the patients with these tumors shows high incidence of radicular pain $(73.6 \%)$, which is rather characteristic compared with other spinal tumors.

During my 12 year stay in U.S., I had an impression that spinal meningiomas were as common as neurinomas, but since I came back to Japan, I was really amazed that neurinomas were by far common in the spinal column in Japan. In my experience in Aichi Medical University from 1981 to 1998, the ratio of spinal neurinomas to meningiomas is 2.6 to 1 , and 17 (50\%) out of 34 spinal neurinomas were located in the cervical spine. Therefore, our data also have the same kind of tendency that the authors presented in this paper.

As clearly demonstrated by the authors, surgical treatment of these tumors is most rewarding among various spinal operations, therefore, we have been employing less invasive approach in most of the cases for the last several years, unilateral laminoplasty using William's saw. This approach definitely decreased patients' postoperative discomfort and facilitated early ambulation and short hospital stay.

\section{Reviewer's comment：小山 素 麿（大津市民病院 脳・神経外科）}

従来の教科書は恐らく欧米のそれをそのまま翻訳されたものと思われ, nerve sheath tumorとmeningioma の発生頻度は同じか，前者がやや多いと書かれていた．著者も引用されているが，病理の報告でも中国の調査 でも4倍に近いほどnerve sheath tumorの頻度は高い. 発生レベルに関しても単に頸髄，胸髄，腰髄の長さか ら胸髄に多いと記載されていた。約70\%は頸髄にあるとされる著者の結果にも賛成で，後根糸に $90 \%$ 以上が発 生する点でも異論はない，神経鞘腫，すなわち硬膜内髄外腫瘍とされず，硬膜外腫瘍もあるとされたことにも 自信が与えられた．臨床症状，手術手技，経過にも学ぶことが多く，その解析の正確さには驚嘆した。

これを機会にわが国のnerve sheath tumorの実態を 1つの施設でなく，多数例を経験した施設のデータを集 積して欧米の真似ごとでなく，わが国独自の解析をしていただきたい. 脊髄腫湯の発生頻度にも人種差が証明 されると確信している. 